I would goand such of $\mathrm{my}$ hearems as aro inexperienced in discumions of thi hind, seainst the impreseion that ceience shows the soul, the conscious principle within us, to be susceptible of any true, actual dinsion. If there be one characteristic which more than another distinguishes the concoious soo from mere body, it is, I conceive, its absolute vinity. Hare we not the same assurance from pure conscioumes, that the me which thinks is not composed of parts, as we have from senso-consciousness that matter is an agregregte of atoms?

Distinctness in the organic instruments implies no corrosponding divisibility in the conscious principle which they subserve. To give expression upon this occasion to the abstract views which I entertain myself upon this subject, I would say that, in all psychical phenomens, the whole mind acts. Mental faculties are states of consciousnessphases only of the one undivided and indivisible mind. It is the whole mind which hears and sees; it is the same entire mind which receives ideas, and recalls them in momory; it is the one thinking entity that loves, fears, and hopes; it is still the same unity, the soul, that performs the highest intellectual operations, in abstracting, combining ideas, ressoning, and judging. Finally, and comprebensively, it is the immaterial spirit which takes cogniance of itself, which controls its own states, and which ตrmis.

\section{ON THE PATHOLOGY AND TREATMENT OF} LARYNGO-TRACHEAL INFLAMMATION.

\section{By ROBERT TURNER, M.D.}

[Continued from page 618.]

$\triangle$ COXPIETE statement of the arguments against tracheotomy in croup is, I believe, comprised in the subjoined extracts:-

"It is not necessary", says Dr. Williams (Library of Medicine, vol. iii, p. 61), "to discuss the question of the propriety of resorting to tracheotomy in croup; as it has been decisively negatived by Dr. Cheyne, Mr. Porter, and other of the best authorities. The trachea of young subjects is 80 small, vascular, and difficult to open; and, above all, the obstructing matter of croup so frequently extends into the bronchi, or cannot be dislodged, even from the trachea, through an incision, that the dangers are many, and the chances of success so few, that in general it can scarcely be said that the performance of the operation is justifiable."

"It has been proposed to perform the operation of bronchotomy", observes Dr. Maunsell (Evanson and Maunsell, On the Management and Diseases of Children, 5 th ed., p. 333), "in croup, with the objects, first, of admitting air to the lungs without the intervention of the larynx; and secondly, of remoring, mechanically, the false membrane from that passage. We have already stated that the inflammation of croup is not confined to the larynx, but extends over the whole bronchial mucous membrane; and Dr. Cheyne has shown that, in fatal cases, a space of more than two-eighths of an inch usually exists in the larynx, for the transmission of air. The patient, therefore, except in cases of sudden spasm, dies, not because air cannot have access to his lungs, but because these organs are unfitted, by their inflamed condition, from performing their own function. Consequently, bronchotomy is unnecessary for the effecting of the first object, and can do no good. As to removing the false membrane, if it could be accomplished, which those who are familiar with the morbid appearances in croup will doubt, the same ultimate objection applies, viz., that we till have the diseased condition of the lungs remaining, and to the remoral of that we contribute nothing by opening the wind-pipe; but, on the contrary, add a new cause of irritation."

"It (Group) is a disease", Dr. Chejne remarks (Cyclopadia of Practical Medicine, vol. iii, p. 23), "in which a murgical operation will only add to the danger to which, in the eccond atage, the patient is expoeed."

"When the aigms of approaching death have come on", arss Dr. Wateon (Lectures on the Privoiples and Precilion of Physic, 3nd ed., vol. i, p. 844), "lividity of the lipe, coldine of the skin, and a tendency to stupor, the queetion will obtrude itself, whether there may not etill be a chance of saring the patient by performing tracheotomy? In the first place, you will consider that the operation is much more difficult to execute upon children then upon edulte and is attended with more perplexing homorrhege. But there is a greater objection than this to tracheotomy in such cases - an objection which you will haro anticipatodnamely, the existence of the preternatural membrane, which often extends so far down, that air rould not be admitted into the lungs, even if an aperture in the windpipe were made at the lowest possible point. Another consideration, forbidding much hope of success from this expedient at any period of the disease, is that the ramifications of the bronchi and the ultimate air-cells get filled up with serous, or mucous or puriform matter, or even sometimes with a membranous exudation, whereby suffocation is effected in the lungs themselves. The membrane in the traches, being tubular, does not entirely exclude the air from these organs, but it does not admit it in sufficient quantity. Tracheotomy has again and again been practised in this complaint to no purpose; and I should be inclined to look upon it as absoIutely hopeloss, but for two instances of its successful performance, recorded in the Medico-Chiruergical Transactions: the one achieved by Mr. Andre, and related by Dr. Farre, in the third volume; the other by Mr. Chevallier, in the sixth volume. They were both apparently hopeless cases. Immediate relief followed the operation in both, and the patients recovered perfectly. ... Unfortunately, we cannot tell, before death, to what degree or extent the preternatural membrane exists. All that can be said, I think, is that when dyspnoes and much croup come on suddenly and quickly, the disease is probably limited to the larynx and upper part of the windpipe; but that when the progress of the disorder is slower, and the croupy symptoms are not so well marked, it is more likely that a greater extent of the trachea, below the larynx, participates in the mischief. Our expectations of success from tracheotomy will vary accordingly. It affords a bad chance, at the best; but it affords, also, in many cases, the only chance."

Speaking of the diphtheritic form of the affection, Dr. Watson remarks: "The comparative freedom of the windpipe wonld encourage a trial of tracheotomy in these cases, when life seemed in jeopardy from impeded respiration; but the morbid condition of the blood, and the resulting character of the attendant fever, forbid the hope of such success from that mechanical remedy as it might otherwise promise."

On the same subject, Dr. Copland (Dictionary of Practical Medicine, art. (roup) thus expresses himself: "There does not seem to be a chance of success from this operation in any case wherein the treatment developed above has failed. The practitioner, however, may be called to a case so late in the disease, and where the suffocation is so imminent, that the propriety of haring recourse to it may be admitted; but, even in these, the chances are infinitely greater against than in farour of its success; and if benefit can be derived from any measure, it is as likely to accrue from the energetic exhibition of suitable emetics, $2 s$ from tracheotomy. Cases have doubtless been recorded of the success of the operation in croup; but these are so very few, compared with the number in which it has failed, that I perfectly agree with Goelis, Cheyne, Royer Collard, Porter, Wood, and many others, in concluding that it should seldom or never be attempted in this disease. Of the propriety of having recourse to it in certain states of laryngitis, etc., there can be no doubt; and it may, with some slight grounds of hope, be resorted to when croup is chiefly confined to the larynx and upper part of the trachen; also, perhapes, in some cases of its consecutive occurrence upon inflammation of the throat with membranous exudation; and when wo infer, from the general ajmptoms and the signs furnished by the stethoscope, that the bronchi and lungs are unaf fected: but in that period of the aimplo as roli as of mont 
of the complicated forms of the disease, in which only it hould be attempted, and when internal treatment has failed, I believe that the superinduced lesions in the bronchi, lungs, circulating fluid, and nervous system, are such as to preclude hopes of its success. Moreover, the feelings of the parents regarding it, and the reputation of the physician and operator, are not to be kept out of view. 'Ad tracheotomiam', says Goelis, 'omnium remediorum incertissimum confugere res ardua est; parentes abhorrent, aversantur agnati, et periclitatur medici fama, quem infausta si fuerit operatio ac votis illudens, lacrymis multis velut hounicidam prolis amatæ detestantur parentes.'"

From a casual expression which occurs in the following passage, and which I take the liberty of distinguishing by italics, it may be inferred that the importance of the glottidean contraction, as an element in the pathology of croup, is partially recognised by Dr. West; but it will be perceived that the hesitating assent which he, in consequence, yields to the employment of tracheotomy in the disease, is virtually withdrawn, almost in the same breath; and that the general tenor of his remarks on this question falls in with those of the other objectors to the measure whose opinions I have quoted.

"It was to be expected", he says (Lectures on the Diseases of Infansy and Childhood, p. 249), " that the probable utility of bronchotomy in cases of croup should suggest itself to the earliest observers of the disease. For many years, however, after it was first advocated on theoretical grounds by Dr. Home, the value of the operation was not put to the test; and even for a long time after it had been tried, but one instance was recorded of any other than an unsuccessful result". [Mr. André's case, noticed above, is here referred to.] "In the year 1825, M. Bretonneau, of Tours, saved the life of a little girl, when in the last stage of croup, by performing tracheotomy; and the operation has since then been performed more than 150 times, and rather more than a fourth of the patients who underwent it recovered. By far the greater number of these successful cases occurred in France; while in Fingland the -osult of almost every instance of the performance of tracheotomy in cases of croup has been so unfavourable, that the operation is scarcely looked on as a justifiable proceeding. The great discrepancy of opinion between French and English practitioners, with reference to the value of tracheotomy in croup, is, without doubt, in great measure due to the very different character which the disease presents in the two countries. In France, croupal symptoms are induced in the majority of cases by the extension to the larynx of the false membrane originally deposited on the fauces and soft palate, while the windpipe itself is comparatively seldom in a state of active inflammation, often altogether unaffected; and the bronchitis and pneumonia, which in this country so often and so seriously complicate the disease, are there of less common occurrence. In estimating the results of tracheotomy in France, it must likewise be borne in mind that, in many instances, the operation was performed on patients whose disease would probably have been amenable to other treatment, and that in some cases the trachea was opened without the previous adoption of any treatment whatever, and quite in the carly stage of the affection.* But, though we cannot infer that all the patients on whom tracheotomy was performed would have died if the operation had not been resorted to, these cases of premature tracheotomy at least prove the operation to be of itself unattended with very serious danger; whilst it is quite conceivable that the relief afforded by it to that spasmodic action of the muscles of the glottis, which endangers the patient's life more than the mere extent of false membrane in the air-passages, may contribute, in a most important degree, to arrest the advances of the disease. But, whatever may be the result of the very early performance of tracheotomy, such a proceeding would be practicable only in a hospital ; and we must base our conclusions, with reference to the operation, on a

* "In Illustration of this fact, two cases mas be noticed, recorded in the 'Journal de la Societé M.édicale d'Inde et Loire', extracted and commento in the "Bull Gtn. do 'Thérapeu tiquo', Ootober 182." due consideration of the circumstances under which alone we are likely to have the opportunity of performing it. 'There is', as Dr. Stokes* has truly observed, 'always that kind of feeling connected with a surgical operation in acute diseases, which prevents its being proposed, assented to, or performed, unless under nearly desperate circumstances, and when all other means have failed. In the case before us, the operation is performed at a time when the situation of the patient is the worst possible for success; when the nervous system has been profoundly injured, and the lungs, even though no primary complication may have existed, have become extensively congested.' Among my patients at the Children's Dispensary, I have never had recourse to the operation; partly for the reasons stated by Dr. Stokes, partly because it would have been impossible in the houses of the poor to command that constant attention and minute care which are absolutely essential to the success of tracheotomy, even when everything in the patient's condition concurs to warrant its performance. Recently, Mr. Arnott performed tracheotomy, at my request, on a boy, aged twenty-one months, who was admitted into the Middlesex Hospital in the last stage of croup, which had succeeded to measles, and which had been allowed to advance without any remedy being employed to check it. In this instance, life was prolonged for forty hours after the operation, and the ingress and egress of air through the canula continued free to the last; but the child's pulse began to grow more frequent and feeble after the lapse of little more than twelre hours, and his respiration became at the same time hurried and laborious, and continued increasingly so until death took place. This being the only instance in which 1 have had the windpipe opened for the relief of the symptoms of croup, it is not in my power to lay down any definite rules with reference to the time or manner of performing the operation. But though I have had almost no experience of tracheotomy in croup, yet it is impossible to have closely watched many cases of that disease without thinking much and anxiously upon the question of performing an operation for its relief. Among the arguments against it, there are two to which the chief importance has been attached. One of these is founded on a statement of Dr. Cheyne's, that three-eighths of the aperture of the larynx have been found free in fatal cases of croup, and that consequently there must have existed during life room enough for the entrance of air. The other is derived from the condition of the bronchi, which, while comparatively seldom free from the disease before the operation, generally, as is alleged, become the seat of increased and more rapidly fatal inflammation after its performance. With reference to the former of these arguments, however, I apprehend that bronchotomy is not performed merely on the mechanical principle of removing from the windpipe a quantity of matter which prevents the entrance of air into the lungs; but that it is done rather to obviate the dangers of that spasm of the glottis which the inflammation occasions, and vohich will not cease until either the inflammation is subdued, or the spasm relaxes with the approach of death. Even the narrow opening made into the trachea-often much narrower than the aperture of the larynx, though diminished by swelling or encroached on by false membrane-suffices, for a time at least, to admit all the air which the patient needs, and the dyspncea is relieved. The inflamed larynx is now at rest; while the air, entering continuously, and without effort, duly oxygenates the blood; and the child is thus placed in a condition in which all remedial agents would seem much more likely to tell upon it, than when it was in a state of impending suffocation. But then this promise of amendment too often is but delusive; the relief is only of short duration; the breathing once more becomes difficult; and death takes place under symptoms of the same kind as existed before the operation, though attended with rather less distress. A measure of euthanasia, then, is all that in many cases is obtained by tracheotomy; while, in the opinion of many, the previous bronchitis is much increased 


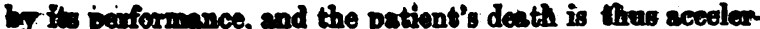
wod Jiast year, howerer, when conrering with M. Trous cans, of Paris, on the subject of tracheotomy, he suggested enother reason for the relapee whieh 80 generally follow eren the most encouraging temporary improvement. Tracheotomy fails, in his opinion, in great mensure because the opening made into the air-passages is too small; air is admitted enough to afford temporary relief, but not enough for the permanent discharge of the functions of the organism ; the return of hurried breathing, the reappearance of the livid hue of the surface, betoken the imperfect depuration of the blood. Take a quill, and, closing your nostrils, endeavour to breathe entirely through it; at first you breathe easily enough, but soon your respiration becomes laborious; and at length you are fain to throw away the quill, and with open mouth once more to fill your lungs completely. Now, precisely this, says M. Trousseau, is what happens when an opening of inadequate size is made into the trachea; air enters readily, and without the interruption which the spasm of the glottis occasioned; but it does not enter in sufficient quantity, and hence the return of the symptoms, and the patient's death. Acting on this principle, he always makes a much larger opening into the trachea, and introduces a much larger canula, than the majority of surgeons; and I mention his opinions and practice, because I think they well deserve your consideration. But now, with reference to the second objection-the uncertainty of the extent to which inflammation of the air-tubes, with possible formation of false membrane, have already extended, and the dangers of aggrarating the already existing bronchitis. It is not possible, I believe, to determine during life the extent to which false membrane may have reached, nor at all easy to estimate the amount of bronchitis; while, against the risk of aggravating it by tracheotomy, we must weigh, on the other hand, the evils of spasm of the glottis, and the effects of unaërated blood circulating through the vessels, if we leave the case alone. Moreover, while M. Trousseau's explanation of the return of dyspncea after the operation may be received as accounting for a part at least of what has generally been attributed altogether to the bronchitis, it must not be forgotten that, in the vast majority of cases, the delicate mucous membrane of the bronchi has been exposed to immediate contact with the cold air of the ward of a hospital, or of a large chamber $-a$ want of precaution to which it is probably not unfair to attribute a large share in the excitement or aggravation of the secondary bronchial inflammation. It appears to me to be worth consideration how far the careful regulation of the temperature of the apartment, and of the condition as to heat and moisture of the air respired by the patient, might diminish the hazard of bronchitis after the operation. And, secondly, it may merit inquiry whether there be any difference to be expected between the result of tracheotomy in cases of sthenic croup, such as formed the basis of Dr. Cheyne's obvervations, in which false membrane was very extensively deposited, and in cases of a more asthenic character, such as the chief of those were that came under my notice among the poor in London, in which the deposit of false membrane was very limited, and the larynx was the chief, sometimes the exclusive, seat of the disease."

I will now recapitulate briefly, and examine one by one, the arguments against tracheotomy in croup comprehended in the foregoing extracts, and forming, as already observed, the grounds on which the measure is condemned by our highest authorities, and well nigh banished from British practice.

1. The expedient is rejected, because the false membrane of croup may extend farther down the tube than the lowest point at which an incision into it can be made.

Against this objection it may, in the first place, be urged that it is not one generally applicable, in accordance with eren the received pathology of the disease ; since it is admitted, that " in mony cases the constriction has appeared grentest where little ar no exudation hes been found aftor death"; this having eacued, as Dr. Mounsell expresses it,

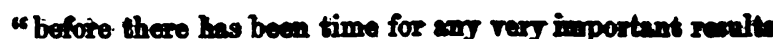
of infinmmation to be produced"; thent in the 10 calied "more spasmodic forms" of croup, thise membrane of opaque exudation " is seldom found, but merely viscid mucus corering patches of rascular redness" in the berynx (Dr. Williams, op. cit., p. 54); and that in the instances in which plastic exudation does occur, it is "much oftener found in the larynx than in the traches" (Dr. West, Lectures, loc. cit.). Is, then, the total rejection of the measure demanded, $\rightarrow$ or is its rejection in any case, where it is fairly indicated, justifiable,-because a possible source of failure may exist, but whose presence cannot be positively ascertained beforehand, or during life? By parity of reasoning, we ought never to remove a scirrhous tumour, seeing that the cancerous diathesis may, notwithstanding, continue to manifest itself; indeed, in my humble estimation, this were a more defensible abandonment of the attempt to cure than the other.

It does not, moreover, seem unreasonable to undertake the operation in the belief that, even if an adherent tubular false membrane lay in the way of the knife, it would be cut through, and form no obstacle to the ingress of air through the canula.

But, in the next place, the tendency of the pathological views abore advanced is to set aside entirely this objection: for they teach us-and Dr. West has, we have seen, arrived at a similar conclusion-that our aim in opening the trachea should be to get under, not the false membrane that may line its interior, but the much more formidable impediment to respiration presented at its entrance,- the glottidean contraction; and in rendering this inoperative by means of tracheotomy, we shall, at the same time, place the lesser difficulties arising from the presence of false membrane in a train for being removed, establishing an outlet for detached portions, and so "obviating the tendency to death" as to permit the conversion of what remains of the deposit into pus, and its ejection in this form.

2. Tracheotomy in croup is further held to be an useless expedient, becanse the access of air to the lungs may be prevented by fluid accumulation in the bronchi and aircells.

In reply to this objection I would submit, that such accumulation occurs only in protracted cases, and may be regarded as the consequence of prolonged constriction of the glottis; and that it, therefore, could not take place if a patent condition of the orifice were maintained, or if the timely substitution for this of an opening in the trachea were had recourse to. For the expectoration of mucus and pus, progressively with their secretion, would thus be permitted, and the pulmonary engorgement-giving rise to effusion of serum into the air-cells-prevented.

3. To the argument adduced by Dr. Stokes, that "the operation is performed at a time when the situation of the patient is the worst possible for success; when the nervous system has been profoundly injured; and the lungs, even though no primary complication may have existed, have become extensively congested", I would answer, that before these adverse circumstances can arise, the hopelessness, or at least the uncertainty, of success from the use of all other meaus will have become apparent; and that the considerations urged by Dr. Stokes ought not, therefore, to induce us to reject the expedient in appropriate circumstances. We do not decide against the operation for strangulated hernia when other treatment has failed, or is likely to fail, because sphacelus of the gut will render the proceeding unavailing when it has been too long delayed.

4. Regarding the alleged contra-indications to the practice of opening the trachea in croup, existing in the state of the bronchi, lungs, blood, and nervous system, Dr. Copland, as we have seen, thus expresses himself: "In that period of the simple as well as of most of the complicated forms of the disease, in which only it (tracheotomy) should be attempted, and when internal treatment has failed, I believe that the superinduced lesions in the bronchi, lungs, circulating fivid, and nervous system aro such as to preclude hopes of its success". Why any operation, at all adsia 
NMe, "shonld be sttempted" only when the diveaces which it is intended to remedy has become 80 compliented "as to prealude hopes of success", I confees my inability to comprehend.

6. But " sccording to the statement of Dr. Cheyne, threeeighths of the aperture of the larynx have been found free in fatal cases of croup, consequently", it is affirmed, "there must hare existed during life room enough for the entrance of air".

The fallacy of this conclusion has been exposed by Dr. West; and, indeed, the notion that a due supply of air is admitted through the rima glottidis in croup,- - keeping in view the meaning of the term,-is one which may be said to carry with it its own refutation. Surely a better reason for adopting the expedient, in appropriate circumstances, than this, which is employed to enforce its unqualified rejection, could not be offered.

6. The risk of aggravating, by tracheotomy, existing bronchial inflammation in croup, or of inducing this when it did not previously exist, is also urged as an objection to the practice.

This argument I would meet by stating my impression, -reasons for entertaining which I have already assigned,that the amount of mucous accumulation found after death is no proper measure of the severity or extent of the preceding bronchitis. I would further submit that this complication, whatever its degree or extent, has, generally speaking, its origin at a late period of the attack, when the time for operation with the best prospect of success from tracheotomy has gone by.

7. The danger of occasioning bronchitis after the operation, by exposing "the delicate mucous membrane of the bronchi to immediate contact with the cold air of the ward of a hospital, or of a large chamber", I agree with Dr. West in regarding as by no means inconsiderable; at the same time, I apprehend that the consequence of such contact, if permitted to take place through the natural channel, in cases where no operation has been resorted to, will not be different. Be that as it may, however, the chances of failure from the cause in question may be much diminished, as Dr. West remarks, by carefully regulating the temperature of the air which the patient breathes. In private practice, it is always difficult, indeed often impossible, to obtain a sufficiently high and equable temperature in the apartment. I have more than once employed as a substitute the plan of adjusting a Jeffrey's respirator to the neck of the patient, over the canula. Perhaps a funnel-shaped appendage of silver-wiro-gauze, closed by a disc of the same material at its widest, and fitting into the mouth of the canula at its narrowest extremity, would be found a more perfect appliance.

I may notice what I conceive to be another probable source of secondary bronchitis, - one more justly chargeable on the operation, although it has not been adverted to by the opponents of tracheotomy in croup, and less under our control than that which has been generally recognised,-I refer to the prolonged contact of the canula with the inflamed lining membrane of the trachea. The danger hence arising must of course be encountered, and admits of being lessened only by watching for and seizing the earliest opportunity of withdrawing the tube.

But the dread of bronchitis, although it may oblige us to moderate, in some degree, our expectations of a fortunate result from the performance of tracheotomy, cannot be considered a sufficient reason for discarding this measure altogether. Here, as in most other emergencies demanding his aid, the surgeon chooses the least of two evils; it is

"From this sume nettle, danger, we pluck the flower, safety";

And it ought to be borne in mind, that in the case under consideration, the question is not between a safe and a harardous mode of treatment, but that if we permit the anticipation of possible evil consequences to stay our hands, ve must accept the alternative of consigning the sufferer to certain denth.

8. Another ground of opposition to this practice is the diffeulty attending the operation, owing to the small size of the windpipe, and the liability to "perploxing hromor rhage" in children.

To this objection the statistics of the operation in France, of which I shall afterwards have occasion to speak more particularly, form a sufficient answer: for the difficulty from all causes of the path to the infantile trachea has often been surmounted by the Gallic knife. The lastnamed source of embarrassment may pretty certainly be obviated by making the incision into the trachea at once, should the hæmorrhage threaten to become more profuse than is desirable (and if no artery of such size as to require deligation previously have been cut), and inserting as large a tube as this opening will admit. I have not found such departure from the rule commonly adopted,-namely, to wait for the spontaneous cessation of the hrmorrhage before opening the trachea.-attended with any difficulty or inconvenience. The lower edge of the cricoid cartilage serves as a sufficient guide to the point at which this incision (cutting from above downwards), ought to be begun, and if the trachea itself cannot be seen it may always be felt. The flow of blood outwards will be restrained by the pressure of the canula; and this can be supplemented, if necessary, by filling the space around with portions of sponge or lint. A little blood may get into the trachea before the tube can be introduced, but will quickly be ejected through it, without materially increasing distress. The first removal of this instrument for the purpose of cleansing it, may (as once happened to me in the case of an adult) occasion a recurrence of the hæmorrhage, which the patient's alarm and struggling, and the violent paroxysm of cough caused by the blood entering the trachea, will very much aggravate. As a precaution against this accident, I keep in readiness a second tube, and insert it immediately on withdrawing the first.

9. Tracheotomy in croup, its opponents aver, has been tried and found wanting.

The results of this measure in France, where "by far the greater number of successful cases have occurred", cannot, it is contended, be admitted as sufficient evidence of its general utility, because the majority of these cases belonged to the diphtheritic variety of the affection, in which the croupal symptoms are induced "by the extension to the larynx of false membrane originally deposited on the fauces and soft palate", and in which, it is said, "the windpipe itself is comparatively seldom in a state of active inflammation, - often altogether unaffected". To this I would, with deference, reply, that since the stridulous respiration and cough are not less severe, and not more amenable to the ordinary treatment in this than in any other kind of croup, it appears quite immaterial, as regards the point at issue, whether the glottidean contraction, of which these symptoms are the exponents, be excited by intlammatory action travelling downwards or upwards. The diphtheritic form of croup is even believed by others* to be that in which the operation is least likely to prove successful. With respect to the alleged comparative immunity from inflammatory action, and consequent membranous exudation, of the trachea itself, in these cases, I must add, that the observation is directly opposed to my own experience, which induces me to consider the rapid extension down the tube of inflammation, with pseudo-membranous deposit, a prominent characteristic of diphtheritic croup. I possess a preparation, consisting of an almost perfect mould of the trachea, and one of the bronchi, of false membrane, which was ejected towards the close of a fatal case of this variety of the disease. It is the largest I have ever seen expectorated.

Another consideration held to invalidate the argument from the statistics of the operation in France in favour of this practice, is the infrequency which, it is said, exists in that country of bronchitis and pneumonia as complications of croup. Leaving unquestioned the fact (although I have yet to learn that it has been asserted on sufficient grounds),

- Soe Dr. Gillespie's remarks on a case of Laryngo-Tracheitis.- " Monthly Journal of Medical Science" for July 1850, p. 30, 
I muat express my unhesitating dissent from the conclusion; for I have already endearoured to shor that tracheotomy, promptly reeorted to when other trestment can no longer be depended on, is a measure calculated to prevent the occurrence of these complications.

Of the one hundred and fifty (chiefly French) cases on record when Dr. West wrote, in which tracheotomy had been employed, and in more than one-fourth of which recovery followed, it is asserted that the operation was performed "in many instances on patients whose disease would probably have been amenable to other treatment", and that "in some cases the trachea was opened without any previous treatment whatever, and quite in the early stage of the affection";* but exact statistical data are, obviously, to be set aside only by counter-statements equally precise. In how many of these cases was the operation performed unnocessarily ? and in how many was it successful when all other means had failed? Above all, why should the teaching of these last, however few, be wholly disregarded ? Satius est anceps auxilium quam nullum.

But, to pass from the consideration of these returns and meet the opponents of tracheotomy in croup on their own ground, have they, I would ask, made the results of the measure in Britain, on which they profess to found their decision, the subject of such careful investigation as the importance of the question demands? If so, why have not the facts elicited by the inquiry, and supporting that decision, been stated ? "Tracheotomy," they vaguely tell us, "has again and again been practised in this complaint to no purpose"; but, on their own showing, tracheotomy has also "again and again been practised in this complaint", and in this country, too, to such "purpose", as palpably to have rescued the subject of it from impending death. The recorded cases of the success of the operation, it is also affirmed, "are so very few compared to the number in which it has failed", that "it should seldom, or never, be atteimpted in this disease". But this ground of opposition to the expedient is here again manifestly rendered powerless by reason of the indefinite terms in which it is urged. The same objection, moreover, will apply with equal force to some of our established surgical operations. If we must reject, on account of its frequent failure, our only resource, when little if at all dangerous in itself, how can we defend the adoption, as a rule of practice, of amputation at the hip-joint, for example $-a$ procedure fraught with much hazard to the patient, and generally unsuccessful ?

"The promise of amendment" (from tracheotomy) " too often is but delusive," says Dr. West; "the relief is of only short duration; the breathing once more becomes difficult, and death takes place under symptoms of the same kind as existed before the operation, though attended with rather less distress. A measure of euthanasia is all that in many cases is obtained by tracheotomy." Is this a fancy sketch? The occurrence in it of such expressions as "too often", and "many cases", with their uncertain sound, forbids the supposition that it has been drawn from life; since Dr. West's own experience on the point is limited, as we have seen, to a single case- that of a boy, aged 21 months, "in the last stage of croup". I shall presently have occasion to show that abundant and, I think, unexceptionable materials for a less gloomy picture are at our disposal.

But further, however little encouragement to pursue this practice may be derivable from British experience, the question arises-Has the operation in all, or in many of the cases of failure with us, been undertaken early enough in the attack to justify any reasonable hope of success? In shunning the Scylla of "premature tracheotomy", on which our brethren in France are alleged to have split, have practitioners on this side the channel steered equally clear of the Charybdis of deferred tracheotomy? Facts are, no doubt, wanting to sustain positively either a negative or an affirmative reply; but it may be observed that received opinions in our own country respecting the pathology of

- The charge of precipitancy, here brought against unr continental neigh. boure sppent to be founded ontirely on the trentment in two cases, to which

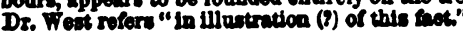

the discase, and the hostility which obtains in high places to the proposed remedy, are circumstances but little likely to conduce to the employment of the latter before an advanced stage of the malady has been reached; and it is also worthy of remark, as confirmatory of the suspicion just hinted, that the measure was rendered by delay a forlorm hope in all the three examples of its adoption at home, which our authors have particularised. It succeeded, notwithstanding, in two of these: "the cases were both apparently hopeless", yet "immediate relief followed the operation in both, and the patients perfectly recovered".* And since we find that this practice will not always disappoint even the slender hope of benefit that can alone be entertained from it in circumstances so unpropitious, surely a. much larger measure of success may reasonably be expected to accrue from its timely employment. We are not, however, shut up to merely inferring its value, when fairly tested; for this has recently been amply demonstrated by M. Trousseau, of Paris, whose views in connexion with this same operation are, it will be remembered, approvingly noticed by Dr. West. In the hands of M. Trousseau, it is stated (British and Foreign Medico-Chirurgical Review, for July 1853, p. 272) two hundred and twenty-two operations. yielded as many as one hundred and twenty-seven cures; \& triumph of the healing art which is probably unparalleled in its annals, insular or continental, as regards the treatment of the severer forms of croup: and the name of this distinguished surgeon must be received as a sufficient assurance that the operation was not here had recourse to in slight cases.

10. One other argument adranced by the opponents of this practice remains to be noticed. I advert to it on account. of the respectability of the source whence it has emanated; but I cannot help regarding this as its sole claim to our attention. It seems almost an insult to the reader's underattention. to observe that the proved or probable inefficacy of a remedial measure is a sufficient reason for rejecting it, and the only justifiable ground of its rejection; but the expedient under consideration is doomed, and, like Scrub's. highwayman, "can't be killed too dead". In weighing its. expediency, therefore, "the feelings of the parents regarding it, and the reputation of the physician and operator", we are told, "are not to be kept out of view"; counsel which, fairly interpreted, involves an assertion of the principle that. the resources of our art may and ought to be withheld when likely to jar with the blind impulses of natural affection, or when they cannot be proposed without risk to the practitioner's popularity! Must the advances of medical science then be subjected to the touchstone here indicated ? Or is the abject subserviency - the dishonest truckling to vulgar prejudice, here inculcated, indeed an indispensable steppingstone or prop to a medical reputation? The history of our profession, in its past and its present, emphatically negatives both suppositions; else had its choicest gifts to suffering humanity perished "as a babe smothered in the birth"; else were Jenner and Simpson names unknown to fame.

After all, the proposed method of conciliating public: favour; even if it were not one that every honourable mind must repudiate, will, I apprehend, be much more likely to fail than to succeed. Few parents could desire to have their: feelings spared at such a price; and the obsequious prophesier of smooth things is in more danger of being regarded velut homicida prolis amatce, than the earnest and conscientious physician who seeks to do his best in fulfilment of the important trust committed to him. Opposition to his measures on the part of patients or their friends will, no doubt, be sometimes encountered by every practitioner;

- My acgnaintance with the records of practical medicine is not sufficient to Hente a complete starement of the published results of this pratio in Britain, but I ch refer to three snecessful cases which have practice the practice of Dr. Duped tho "Iondon and Edinburgh Dunsmure, of Edibure concluMonthly Journal of scedical scienco" lor $1848, p$. . sion that the operation was the means of preserving ife, soems perfoch legitimate one; and I believe the evidence nf its utility in the instance givea below (Case II), although the circumatences leading to its of 
but from the intelligent part of the community, at least, I believe he will much of tener meet with a ready acquiescence in any proposal he may deem it his duty to make. One painful instance, occurring in my practice before the views submitted in this paper were formed, is fresh in my remembrance, in which the opposition to the expedient I now adrocate was all on my own side. The case was one of sthenic inflammatory croup which terminated fatally, notwithstanding the energetic employment of the usual remedies. When the inefficacy of these had become apparent, I was implored by the anxious father of the little sufferer to give his child the chance of recovery, if I considered that there was any, afforded by the resource in question. To my lasting regret, I bowed to the decision of authority, and the appeal was made in vain.

[To be continued.]

Keith, July 1834.

\section{BIBLIOGRAPHICAI NOTICES.}

Letrooxian Lectores on Irsanity. By Forbes Winslow, M.D., D.C.L. pp. 160 . London: 1854.

These Lectures contain much information, and no one can read them but with pleasure and profit. Their style, though clear and agreeable, is, however, somewhat diffuse and too elaborately ornate.

The Lectures are three in number, and were delivered before the Medical Society of London, during last season. The first is on the psychological vocation of the physician; and, with reference to this subject, the lecturer makes the pertinent remarks that follow:-

"To the physician specially occupied in the investigation of the deranged conditions of the mind, how indispensable is a knowledge of mental philosophy! Unless acquainted with the constitution of the human understanding, we are but ill adapted to unrarel or appreciate the intricate phenomena of its disorder action, or to apply for their eure or alleviation those medical and moral agents which advanced science has placed within our reach. Before the morbid mental state can be diagnosed or understood, it is necessary for the physician to be intimately conversant with some normal standard of comparison, otherwise he possesses no test by means of which he can arrive at a safe conclusion. Who would confide in the judgment of a physician who endeavoured, by means of the stethoscope, to ascertain the nature of any particular disease of the heart and lungs, if he were ignorant of the normal action of these organs? Is not a knowledge of the healthful operations of thought as necessary to the physician who is called upon to pronounce whether, in any given case, an apparently suspicious deviation from the normal condition of the intellect is or is not the effect of disease?" (p. 17.)

The subjoined observations, which occur in the second Iecture, on the Medical Treatment of Insanity, may be studied advantageously by a wider range of readers than the class of physicians especially deroting themselves to psychological medicine :-

"Admitting the great utility of the microscope, I would, placing my interrogatory in a suggestive form, ask whether we pave not, in these profound, intellectual, and necessary investigations, occasionally overlooked the great and ostensible vocation of the physician? The erudite anatomist, the learned physiologist, the accurate stethoscopist, the profound analytical chemist, the zealous microscopist, capable of accurately delineating the minute anatomy of tissue, or the physical character, weight, and quality of each essential organic element constituting its and will not, without the patient study of the phenomens of disease, and careful investigation of the modus operandi of the ants of the materia medica in certain morbid conditions of the system, make either a good or a successful physician. Five we not neglected the study of therapeuties? Have we deroted anticient dogree of attention to the study of the specific sction of medicines under given conditions of bodily disense? Have we endeavoured to discover the most speedy mode of arresting the disorganising process, assuaging suffering, prolonging the duration of life, and averting death, by the persevering administration of physical curative agents ?" (pp. 47, 8.)

The third and last Locture forms a most excellent disquisition on Medico-legal Evidence in Cases of Insanity, and we strongly recommend its perusal to all who may have to give medical testimony in these instances. We cannot call to mind the perusal of anything upon the subject, that we have found more useful, and at the same time more pleasing. Nerertheless, there art several points upon which we must dissent from the author.

Dr. Winslow repudiates, or greatly disparages, at least, the indications of insanity supplied by the loss of a just appreciation of "right aud wrong"; and, dealing with what he deems to be the ragueness and uncertainty of any such test, he says:-

“ The right of to-day, in matters of theology, philosophy, and science, may be the wrong of to-morrow; and what is now 'lawful' may, in the course of a short parliamentary session, be made illegal by the introduction of new statutes! Analysing this much eulogised legal test as metaphysicians, as medical philosophers, and as men of the world, are we not compelled to pronounce it to be worthless and practically inapplicable?" (p. 107.)

But the question concerns the sentiment of moral obligation. Dr. Winslow, in the above passage, makes universally true, what is only so of the accidentally "right and wrong". Circumstances which conventional regulations allow, or disallow, and so make them right or wrong, must in themselves be neither good nor evil, as gratifying or wounding the moral sense ; and conscience, in regard of such matters, is acted upon by appreciation of the obedience due to lawful authority, and not by contemplation of things that may one year be lawful and another unlawful. Ideas of duty everywhere act, more or less, upon the corresponding emotion; and an absolute defect suddenly arising in this particular, is of undoubted importance in the diagnosis of insanity. It is by no means "worthless" or "practically inapplicable", as Dr. Winslow may discover, if he compare a person, presumably insane in this respect, with his former self.

We demur, moreover, to the logic involved in the following proposition, which the author emphasises by italics : it reminds us of the vicious circle. Summing up an argument, he says:- "No notion of the mind, however ridiculous, illogical, fallacious, and absurd, should be admitted to be a delusion, or evidence of unsound mind, unless it be obviously and unmistakeably the product of a diseased intellect." (p. 146.) But how shall we diagnose the diseased intellect in some cases, if abstraction be made of the evidence supplied by the character of the notion itself? Insanity, like other diseases, is recognised by symptoms; and, in numerous cases, the delusive notion furnishes, if not the only symptom, at least the prominent and tho essential one.

However, we adduce these littie short-comings hardly as blemishes; we mention them, in some degree, to evidence the interest and attention with which we have gone orer Dr. Winslow's truly instructive work, which, in conclusion, we heartily recommend to our readers.

Treatige on the Coltivation of the Vine in Pots. By R. ELPHinstore. pp. 32 . London: 1854 .

THIs little brochure gives a clear account of a method by which ripe grapes can be put on the table in seven or eight months from the planting of the slip or eye of the vine in a pot. We recommend it to the notice of such of our brethren as delight in horticulture. 